\title{
Joan Rivière, la mascarada y la disolución de la esencia femenina
}

\author{
Patricia Amigot \\ Universidad Pública de Navarra \\ patricia.amigot@unavarra.es
}

Al principio hay un fin. No temas: es tu muerte la que muere. Después: todos los principios.

Hélène Cixous (1986)

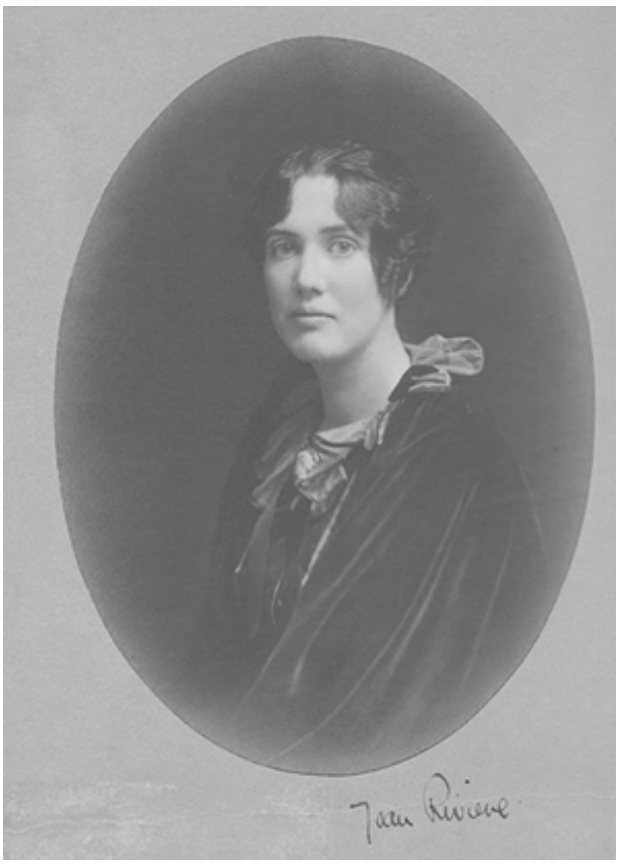

\section{Introducción}

La obra de Sigmund Freud significó la irrupción en el pensamiento occidental de un nuevo dispositivo discursivo, el psicoanalítico, cuyos efectos en la conceptualización de lo social y de lo subjetivo han sido de gran magnitud. Su obra estableció nuevos cursos de reflexión y de análisis que, más allá de rechazos críticos o de ceremoniosas repeticiones, siguen obstinadamente vivos y abiertos en el pensamiento actual, como lo muestra, entre otros, el trabajo de Judith Butler o Slavov Zizek. El deseo, los procesos inconscientes, las identificaciones y las ficciones subjetivas serán algunos de los tópicos abordados una y otra vez desde perspectivas y herramientas diversas del psicoanálisis. En la actualidad, además, algunos desarrollos teóricos indagan, utilizando herramientas conceptuales psicoanalíticas, en los procesos sociales de constitución de las subjetividades y en la operatividad subjetiva del poder. A lo largo del siglo XX y hasta la actualidad las cuestiones acerca del desarrollo psicosexual, y de esos inciertos términos como feminidad y masculinidad, han sido objeto de grandes controversias, tanto en el interior de la comunidad psicoanalítica como en las discusiones que otras corrientes de pensamiento, especialmente los desarrollos feministas, han dedicado al Psicoanálisis.

Joan Rivière, psicoanalista inglesa nacida en 1883, perteneció a esa generación de discípulos de Freud que participó en la constitución y ampliación de la primera comunidad psicoanalítica, y que lo hizo incidiendo en la propia obra de Freud, hasta que éste murió en 1939. Con el crecimiento de la familia psicoanalítica, las tensiones y conflictos -a los familiares se dedicó en cuerpo y alma el corpus psicoanalítico- también se multiplicaron. Una de estas controversias, la que se desarrolló durante las décadas de los 20 y 30, giró precisamente en torno a la sexualidad femenina y a los avatares del desarrollo psicosexual, más concretamente en torno al complejo de castración que Freud planteó para analizar el proceso edípico de las mujeres. En esta controversia, denominada en ocasiones la 
polémica "Freud-Jones" -puesto que fue Ernest Jones quien más la sintetizó-, se confrontaban, de manera no monolítica, la importancia concedida por Freud a la castración, por un lado, con quienes destacaban las etapas femeninas anteriores al Edipo por otro, dicho muy esquemáticamente.

"No nos podemos situar en la perspectiva analítica sin la emergencia permanente de la contradicción", dice Silvia Tubert (Tubert, 1988, p.12) y la propia obra de Freud serpentea entre paradojas y ambivalencias. Su teorización de la sexualidad femenina, también. Esto, obviamente, tiene relación con el contexto histórico y epistémico del que se desprende su obra y que, en cierta forma, también transgrede. Una matriz epistémica cuyos aprioris vinculados con la construcción moderna occidental de lo masculino y de lo femenino operaban mediante oposiciones dicotómicas y comparaciones jerarquizadas. Como el ordenamiento de sentido establecido por estos regímenes de saber/poder homologaba lo humano con lo masculino, cualquier abordaje de la diferencia desde esos parámetros configuraba a ésta simultáneamente como carencia, desviación e inferioridad, y la relegaba a ese espacio teórico ambivalente en el que la feminidad es, a la vez, un misterio y una evidencia sobredeterminada. Con una filiación tal, no es extraño que las primeras controversias del psicoanálisis giraran en torno a la sexualidad femenina y que esos enraizamientos epistémicos generaran, en la obra del propio Freud, frecuentes contradicciones entre reiteraciones androcéntricas y formulaciones más lúcidas.

\section{La primera controversia sobre la sexualidad femenina}

El psicoanálisis ha tenido una larga historia de confrontación e interrelación con el feminismo teórico. Los inicios del movimiento feminista de final del siglo XIX y principios del XX influyeron en el interés que las elaboraciones psicoanalíticas dedicaron a la sexualidad femenina $y$, también, a disciplinar y clasificar a las mujeres que se rebelaban contra las normas de género que definían la feminidad burguesa. Pero al mismo tiempo, mujeres cultural y políticamente radicales como Helene Deutsch o Karen Horney, entre otras, se acercaron al psicoanálisis en tanto significaba un cuestionamiento de valores y concepciones establecidas, (Flax, 1990). Se puede sostener que la obra de Freud leyó un malestar femenino arraigado en el orden cultural hegemónico del momento.

En este contexto se dio la primera controversia psicoanalítica en torno a la sexualidad femenina. Freud había planteado un desarrollo similar en niños y niñas -postulando una bisexualidad libidinal común, en tanto las pulsiones siempre son activas y la libido no tiene sexo ${ }^{1}-$ hasta la entrada en el complejo edípico. Este nudo afectivo era decisivo para las identificaciones sexuales, la organización de la genitalidad, la elección de objeto y la articulación de las instancias psíquicas (ello, yo y superyo). Según el autor, aquello que permitía la resolución del Edipo en el niño -a través de la renuncia al objeto amado, la madre, y la identificación con el padre- era la amenaza de la castración, vinculada a la prohibición paterna. Este análisis, obviamente, condujo a Freud al interrogante subsidiario acerca de cómo se desarrollaba tal complejo en las niñas, que no podrían sentir la amenaza de perder algo que no tenían. De ahí viene la polémica noción de envidia de pene, y esa ecuación simbólica "deseo de pene= deseo de niño" que sería postulada como la clave para el cambio de objeto amoroso (de la

\footnotetext{
${ }^{1}$ Aunque, asimismo, esta similar economía libidinal en la entrada a la fase fálica, le llevara a decir que "la mujercita es un hombrecito" al extraer de su pequeño clítoris sensaciones placenteras y estados de excitación. Sólo un apriori implícito en torno a la pasividad/actividad y al recorte y clasificación de los órganos femeninos podría llevar a tal consideración grotesca.
} 
madre al padre) y la posibilidad de identificación con la madre. Sin ninguna duda, la descripción que hacemos es muy esquemática y merecería más espacio.

Freud subrayará que lo masculino y lo femenino no son puntos de partida ni características biológicas o innatas, sino que se constituyen como resultado de complejos procesos afectivos inconscientes. Es evidente la ambigüedad teórica que aquí opera al hacer pivotar su explicación, simultáneamente, sobre la percepción por parte de la niña de una inferioridad biológica que es una proyección de los significados sociales que construyen el sexo, como apuntaría después una de las más brillantes psicoanalistas, Karen Horney (1967). En muchos desarrollos psicoanalíticos -también en el estructuralismo de Levi-Strauss- aparece esta misma paradoja: la de presuponer la subordinación que pretenden explicar (Tubert, 1988).

Curiosamente, en la controversia de aquellos años en torno a la sexualidad femenina, fondo contextual del artículo de Rivière, los críticos de las nociones freudianas de envidia de pene y de la castración, recurrirán en muchas ocasiones a postular rasgos femeninos innatos, tendencias biológicas en las niñas, anteriores al Edipo. Aunque apuntaron la importancia de la relación preedípica de la niña con la madre, algunos desarrollos críticos con Freud constituyeron una escalada asombrosamente biologicista: Ernest Jones afirmó una feminidad primaria en la niña citando textos bíblicos; Karen Horney -a pesar de su crítica cultural- postuló un "principio biológico de la atracción heterosexual"; Helene Deutsch hablará del carácter instintivo pasivo y masoquista de la sexualidad femenina. ${ }^{2}$ Freud, con su consideración de las convenciones y normas sociales en el desarrollo de la feminidad, con la importancia que concedió a los significados y representaciones psíquicas y con su insistencia en una vida pulsional indiferenciada y activa, mantuvo, a pesar de todo, una postura problemática para la ideología de la época y crítica con la tendencia al cifrado de la sexualidad femenina en claves biológicas de algunos de sus discípulos. "Me opongo a todos vosotros en la medida en que no distinguís más clara y netamente entre lo que es psíquico y lo que es biológico, en que intentáis establecer un paralelismo neto entre ambos [...]", escribió en julio de 1935 (cit. por Mitchell, 1974).

Esta oscilación entre la reificación biológica de lo femenino/masculino, por un lado, y la alusión a los procesos de interacción, con sus dimensiones simbólicas y fantasmáticas, por otro, ha sido analizada críticamente. Destacaremos dos consideraciones imprescindibles. En primer lugar, que es necesario historizar y analizar genealógicamente el dispositivo psicoanalítico. Como Michel Foucault señaló, el psicoanálisis se suma a las producciones epistémicas de la época y a su operatividad como saber/poder; las novelas familiares del psicoanálisis aparecen en un momento en el que la familia burguesa se ha ido saturando de sexualidad -en contraposición a la importancia del linaje de la aristocracia- como elemento decisivo en el desarrollo del biopoder, en su doble ejercicio sobre el cuerpo social y sobre los cuerpos individualizados, durante el siglo XIX ${ }^{3}$ (Foucault, 1976). Es decir, el psicoanálisis opera dentro de un modo histórico de subjetivación y participa de él (Fernández, 1999). En segundo lugar, al margen de considerar valiosos muchos desarrollos psicoanalíticos, es necesario sospechar de las totalizaciones o elevaciones a categoría de universal de cualquier planteamiento; podemos pensar que "cuando se postula un orden simbólico universal, ajeno a toda contingencia

\footnotetext{
${ }^{2}$ Véase: Flax, 1990; Mitchell, 1974; Tubert, 1988.

${ }^{3}$ Esto le hizo decir a Foucault que lo que admiraba en la obra de Freud era el descubrimiento y análisis de los procesos inconscientes, no tanto su teoría de desarrollo psicosexual que no era sino continuación de los discursos hegemónicos del siglo XIX (Foucault, 1977). Aunque también podría verse en la reconceptualización de la histeria que hace Freud una ruptura muy significativa con éstos.
} 
histórica, corremos el riesgo de trasponer lo imaginario a lo simbólico y confundirlo con un orden social dado" (Tubert, 1988, p.13). Y eso, además de una confusión, es una operatoria política que incita determinados modos de subjetivación.

\section{Un destello en el texto de Joan Rivière: la feminidad reconsiderada.}

De alguna manera, tanto la obra de Lacan como las reflexiones más actuales de algunas teóricas feministas tienen un importante antecedente genealógico en el texto de Joan Rivière. Teniendo como trasfondo la controversia aludida, Rivière escribe en 1929 La feminidad como máscara. Este texto supone una sutil vuelta de tuerca en el debate del momento sobre la feminidad y, en su gesto preciso y leve, avanza en la disolución de los aprioris de tal debate para pasar a otra cosa; a permitir, y el efecto retardado del texto da cuenta de ello, reformular significativamente los impensados de la controversia. La feminidad como máscara, aunque se inserta y sostiene, sin duda, los planteamientos del momento, inicia un desplazamiento en la consideración de la feminidad que es interesante releer y rescatar.

Joan Rivière nació en 1883 y hasta su matrimonio fue Joan Verrail. Pertenecía a la gran burguesía intelectual inglesa. Estudió en Gotha y Cambridge y su dominio del alemán la llevó a colaborar con James Strachey en la traducción de las obras de Freud al inglés ${ }^{4}$. En 1919 participó en la fundación de la British Psychoanalytical Society. De 1916 a 1920 se psicoanalizó con Ernest Jones, después con Freud y más tarde con Melanie Klein, con quien trabajará largo tiempo en Londres. La relación con Jones fue complicada -según algunos autores, constituyó posiblemente una relación amorosa (Heath, 1986)-. Fue él quien derivó su análisis a Freud y la recomendó en una carta en la que describe su proceso en términos de "un caso típico de histeria", "anestesia sexual" y "angustia desorganizada"; en otra ocasión, Jones dirá a Freud que, a pesar de no ser un tipo de mujer que le atraiga eróticamente, "ciertamente tengo una admiración por su inteligencia como la que podría tener con un hombre" (cit. por Heath, 1986). No es difícil sospechar los contrabandos androcéntricos que sostienen tales consideraciones, ni los presupuestos epistémicos de la época que enlazaban monolíticamente sexo-género-orientación sexual. Esto último es fundamental para comprender el texto de la propia Rivière. En aquel momento, la ordenación de sentido operada sobre lo masculino y lo femenino implicaba un uso del término "homosexualidad" como inversión de género. Por eso, las mujeres que desempeñaban roles activos o intelectuales eran percibidas como masculinashomosexuales y la explicación psicoanalítica de ello remitía a complejos procesos identificatorios con las figuras paternas. Como las palabras de Jones expresan, la inteligencia de algunas mujeres es reconocida y valorada, aunque tal reconocimiento se realice mediante la comparación de esta "desviación" con la norma masculina.

La feminidad como máscara comienza, precisamente, con la alusión al trabajo de Ernest Jones. Reconoce las aportaciones de éste y la deuda con las elaboraciones teóricas -obstinadamenteclasificatorias de Jones. Rivière pretende indagar acerca de "un tipo intermedio" de mujer, de desarrollo heterosexual pero con manifestación de características masculinas. Los presupuestos

\footnotetext{
${ }^{4}$ A ella se debe la traducción de El malestar en la cultura como 'Civilization and its discontents' y que se desestimara la sugerencia del propio Freud: 'Man's disconforts in civilization'.
} 
sobre la masculinidad y la feminidad que tejen la mirada analítica, junto con la necesidad de abordar los desafíos que las transformaciones de las mujeres plantean, hacen que la compulsión clasificatoria se multiplique hacia un horizonte sin sentido. En el caso de Rivière, puesto que no impugna directamente los presupuestos epistémicos, el sinsentido de la clasificación aparecerá formulado como enigma: "es realmente un enigma saber cómo clasificar psicológicamente este tipo de mujeres". Aunque no rechaza la estrechez de las categorías de manera frontal, sí señala dos cuestiones sumamente importantes y efectivas: que los "rasgos característicos homosexuales o heterosexuales son el resultado de una interacción de conflictos y no necesariamente la prueba de una tendencia innata o fundamental"; $\mathrm{y}$, -marcando una diferencia con el contexto sociohistórico anterior, "esto ahora ha cambiado"-, que "de todas las mujeres que actualmente trabajan de manera profesional, sería difícil decidir si la mayoría de ellas son más femeninas que masculinas en sus personalidades y estilos de vida". Las categorías y clasificaciones, deudoras de un orden social determinado pero con pretensiones de universalidad, hacen aguas y muestran su dimensión específicamente política cuando son confrontadas con la multiplicación práctica que las desborda.

En este texto, para algunos autobiográfico (Hughes, 1997), la mujer exitosa pero angustiada que profusamente describe Joan Rivière es construida sobre dos trasfondos: el de las pasiones e identificaciones infantiles inconscientes -esos juegos de envidias, usurpaciones, imposibilidades y castigos temidos-, por un lado, y el de las dinámicas sociales que prescriben papeles genéricos para después sancionarlos como naturales, por otro. Es este último el que queremos destacar aquí. El texto de Rivière parece funcionar como un texto "bisagra" que opera un desplazamiento luminoso desde la "psicologización" y "familiarización" de los conflictos hacia la consideración de las tensiones y relaciones de poder sociales que demandan y castigan una feminidad no adecuada. La angustia, que ha sido vinculada en las obras psicoanalíticas a la "castración", a la "envidia de pene" y a esa trama de pasiones triangulares, deviene en el texto de Rivière, de manera imperceptible pero decisiva, en angustia por las represalias que el orden social y las relaciones de poder en él establecidas pueden desencadenar. La máscara aparece como una defensa; pero, en esa reconsideración de la feminidad que ella realiza, es más que una defensa: como estrategia contra "la ansiedad y las represalias", la feminidad es resituada en el ámbito de las prácticas y de las definiciones sociales y pierde así su carácter esencial y ontológico. "Mi intención -escribe- es demostrar que las mujeres que añoran su parte masculina, se ponen una máscara de feminidad para evitar la ansiedad y las represalias que temen de los hombres".

La angustia que actúa en el proceso descrito no se desprende del hecho de no ser femenina; con cierta ingenuidad asevera que "nos encontramos mujeres que parecen cumplir con todos los criterios del desarrollo femenino completo" y enumera una inacabable secuencia de actividades en las que se cifraría ese desarrollo adecuado; la angustia se vincula con el desarrollo de prácticas y posiciones que exceden los ordenamientos sociales de lo femenino y las tensiones que ello genera. A pesar de ser muy buenas mujeres, las transgresiones y los desbordamientos de la categoría son problemáticos. Si el ejercicio de la feminidad es defensivo (mostrar que no se sabe, seducir de la manera adecuada, "disfrazarse de alguien inocente e inofensivo"), si es una mascarada, la feminidad se muestra como una actuación que se ha desprendido de sus anclajes esencialistas. Ello la lleva a plantear su aseveración más destacable: "el lector podrá tal vez preguntarse ahora cómo defino la feminidad o dónde trazo la línea que separa la genuina feminidad de la «máscara». Sin embargo, mi opinión es que no existe tal distinción; ya sea de manera radical o superficial, son una misma cosa" (el énfasis es nuestro). 
Podríamos pensar que las clasificaciones y las tipologías son impugnadas con astucia no desde la negación frontal sino desde la parcial asunción de éstas para llevarlas a los límites y ahí hacerlas estallar. Hay una espléndida lucidez en la conclusión de Rivière acerca de la naturaleza de la feminidad, una paradójica inteligencia que se desata cuando en estas frases, sin grandilocuencia, desbarata aquello desde lo que partía. Sin embargo, al final del artículo insiste en el esquema previo y parece dejar en suspenso sus propias reflexiones cuando formula la pregunta: “¿Cuál es la naturaleza esencial de una feminidad completamente desarrollada?".

Los destinos de los hallazgos más lúcidos de Joan Rivière aparecen en la obra de otras personas que han retomado la idea de la mascarada para desarrollarla y reactivarla de formas muy diversas. Aludiremos muy esquemáticamente a alguno de estos devenires.

\section{"Son una misma cosa": de la mascarada a la falta del sujeto.}

Jacques Lacan lee a Freud y destaca su reflexión en torno a la castración. Desde la perspectiva simbólica, el planteamiento freudiano de la castración incide por igual en ambos sexos, dando cuenta de la ruptura del narcisismo que se sitúa en el origen de la construcción del objeto como perdido o ausente y de la constitución del sujeto en tanto escindido (Tubert, 1988). Por eso Lacan hablará de sujeto en falta. Asimismo, Lacan traduce el texto de Rivière en 1957 y reelabora a partir de él esta idea de una máscara que no encubre ninguna verdad, que es ella misma la verdad. En su compleja obra, muchas nociones tendrán un "aire de familia" con la mascarada: semblantes, comedia de los sexos o su conocida afirmación "la mujer no existe". La falta de esencia, asimismo, aparece en la reformulación de la afirmación freudiana acerca de una libido que no tenía sexo mediante su famoso aforismo "no hay relación sexual"; la diferencia sexual no puede escribirse en lo real, no hay complementariedad entre los sexos, es decir, no hay manera de escribir la diferencia sexual que no sea con los significantes (Carbonell y Segarra, 2002). Lacan establecerá unas complejas fórmulas de sexuación, de las cuales no podemos dar aquí cuenta, cuyo devenir está sostenido por la falta. Tanto la posición femenina como la masculina son semblantes que no ocultan sino la no-identidad sexual. Subrayando la importancia concedida a los procesos de identificación, algunas autoras resaltan la operatividad del orden social en estas fórmulas, puesto que las identificaciones se dan con significantes que adscriben al sujeto a unos ideales culturales (Tubert, 1988).

No obstante, no deja de ser problemática la consideración dicotomizada de las posiciones sexuadas aunque estas no se remitan de ninguna manera a lo biológico-, o el uso de un término como el de castración, genealógicamente enraizado en un orden social determinado. Las derivas de los interrogantes en torno a estos usos son diversas y prosiguen. La castración, en tanto enunciación de la falta, del límite, de la no-identidad, de aquello que nos vincula a los otros y a un orden simbólico, es resignificada con otros nombres en las obras de algunas autoras feministas como Teresa De Lauretis o Judith Butler (De Lauretis, 2000; Butler, 1997). Asimismo, las controversias en la consideración de la diferencia sexual como real o, por el contrario, como simbólica, han dado lugar a interesantes debates teóricos como los protagonizados por Slavov Zizek, Joan Copjec y Judith Butler (Butler, Laclau, Zizek, 2003; Copjec, 2006; Zizek, 1996). En ocasiones, como creemos que sucede en los debates señalados, sólo las posiciones no dogmáticas permiten el diálogo o la elucidación mutua. Y no está de más sospechar que toda alusión a un orden simbólico que se pretenda universal quizá no 
sea sino la alusión a una modalidad de la contingencia, como advierte Silvia Tubert (2003), aunque opere y tenga efectos claros en la configuración de las identidades femeninas y masculinas

\section{"Son una misma cosa": la feminidad actuada y la performatividad de género}

Si la feminidad, como señala Rivière, es esa máscara con un guión vinculado a códigos normativos sociales y ontológicamente endebles, entonces estamos hablando de las prácticas y actuaciones desplegadas para ser aquello que los códigos sancionan como adecuado y luego naturalizan. Esta dimensión performativa se ha constituido como el punto nodal de los desarrollos más recientes dentro de la teoría feminista. Obviamente, el texto de Rivière no es sino uno de los antecedentes que han precipitado un análisis original y muy sólido de los dispositivos de género. Además, en estos desarrollos recientes, la "mascara" actuada ha sido puesta en relación no solo con la feminidad sino con el género como sistema histórico que configura feminidades y masculinidades. El género, tal como Judith Butler o De Lauretis y los desarrollos de la Teoría Queer han mostrado, es una construcción cultural, una elaboración política que se configura en su propia performatividad.

Desde estos enfoques, la identidad de género es un efecto de dispositivos que enuncian performativamente una realidad identitaria y articulan una red de prácticas en las que las identidades -y los cuerpos- se construyen reiterándose. Es esta reiteración la que tales dispositivos naturalizan y en este proceso crean la ilusión de una esencia. Por ello, dirá Butler, el sexo "tal vez fue siempre género" (Butler, 1990, p. 40). Muchos análisis feministas actuales han abierto un profundo debate en torno a las nociones de sexo y género que la propia teoría feminista ha utilizado y utiliza, convirtiendo esta discusión en un fértil espacio para pensar la constitución de los cuerpos y de las identidades.

La pregunta por los mecanismos psíquicos que sostienen los dispositivos sociales de género aparece como un espacio teórico complejo (Butler, 1997). Las dos líneas de mayor espesor reflexivo tienen que ver con la cuestión de la transformación y la subversión -¿cómo alteramos esas prácticas reiteradas que nos constituyen?- y con los procesos afectivos y corporales que sostienen las dinámicas de las identificaciones que, a su vez, regulan la implicación y el apego a los códigos normativos performados. Es, quizá, esta dinámica entre el deseo y el poder, que ha sido un gran impensado de los psicoanálisis, una de las encrucijadas más interesantes de ciertos planteamientos actuales.

El texto de Riviere se sostiene en dudosas clasificaciones que condicionan y estructuran la percepción de las características (masculinas, femeninas), y que postulan una muy problemática unidad entre atributos de género y "orientación naturalizada" (Butler, 1990, p.85). Rivière habla de mujeres que "añoran su parte masculina" y la añoranza se remite a las complejas relaciones afectivas de la infancia. Más allá de impugnar necesariamente los presupuestos epistémicos androcéntricos y heterocénticos, es interesante dejar abierta la pregunta sobre qué procesos subjetivos sostienen las identificaciones y las actuaciones; sobre ese espesor emocional que opera en la performatividad y que no se puede circunscribir a los conflictos edípicos, sino que se articula en los contextos históricos que regulan, como diría Michel Foucault, las ontologías posibles de cada época 


\section{A modo de conclusión}

Volviendo al texto de Joan Rivière, podríamos decir, paradójicamente como ella misma, que "hoy todo ha cambiado"; sí, desde luego, en la apertura epistémica que permite la reconsideración de la reificación de lo femenino y lo masculino y de las identidades. Acontecimientos teóricos y de orden social han transformado profundamente las herramientas de análisis y las prácticas de constitución subjetiva. Es problemático a estas alturas hablar de la mujer en singular, o utilizar dualidades reificadas como masculino/femenino, homosexual/heterosexual. Pero -aunque los análisis variarán según el contexto- los imaginarios sociales y los discursos hegemónicos, en su operatividad de saber/poder, siguen construyendo identidades sexuales, por más que sus ejes y efectos no sean aquellos que describía Rivière en su época. A pesar de una mayor diversidad en los referentes identitarios y de la emergencia de saberes que impugnan las relaciones de género, pueden observarse en el ámbito social las expectativas y las limitaciones que producen los imaginarios y los imperativos culturales sobre el cuerpo femenino, y los vínculos ambivalentes y conflictivos que la doble normativa de género produce.

Michel Foucault exploró las relaciones de poder productivas y las prácticas de subjetivación con ellas relacionadas. Judith Butler prosigue ese análisis del poder en su doble valencia de subordinación y producción y pretende un análisis explícito del poder en relación con la dimensión de lo subjetivo, esa dimensión no transparente que late en deseos o motivaciones encarnadas y opacas (Pujal, 2006). Siguiendo la lógica de Butler, que establece el sexo como construcción de los dispositivos sociales de género, la inteligibilidad de los sujetos está marcada por las dinámicas hegemónicas de género. Esto implica que el poder sanciona a aquellos cuerpos no asimilables por tal dispositivo como abyectos (Butler, 1990) y que sigue explotando las dimensiones relacionales y de vulnerabilidad de los cuerpos -entendidos como entidades semiótico-materiales- para la configuración de identidades sexuales normativas. Las relaciones de poder establecen criterios de valoración y reconocimiento que siguen operando, en ocasiones de maneras ambivalentes y precarias, aunque hayan sido impugnados y combatidos. "Cada cuerpo se produce y reproduce en el complejo anillado de múltiples marcas. Marcas deseantes, pero también histórico-sociales; biológicas pero también políticas; pulsionales pero también de lenguaje" (Fernández, 2006, p. 248). Es esta compleja situación que imbrica prácticas y discursos sociales en su interacción con los cuerpos y su dimensión libidinal y creadora de la que Joan Rivière habla a su manera y en su tiempo. La que merece la pena seguir analizando y subvirtiendo, para problematizar viejos y nuevos esquemas, sin eludir las tensiones que las preguntas por el deseo, los procesos subjetivos y el género como dispositivo de poder, provocan.

\section{Referencias}

Butler, Judith (1990). El género en disputa. El feminismo y la subversión de la identidad. MexicoBuenos Aires-Madrid: Paidós. 2001.

Butler, Judith (1997). Mecanismos psíquicos del poder: Teorías sobre la sujeción. Madrid: Cátedra. 2001.

Butler, Judith, Laclau, Ernesto, \& Zizek, Slavov (2000). Contingencia, hegemonía, universalidad. Diálogos contemporáneos en la izquierda. Buenos Aires: Fondo de Cultura Económica. 2003. 
Carbonell, Neus, \& Segarra, Marta (2002). Psicoanálisis y diferencia sexual. Lectora. Revista de dones i textualitat, 8, 7-11.

Cixous, Hélène (1986). La llegada a la escritura. Buenos Aires: Amorrortu. 2006.

Copjec, Joan (2006). El sexo y la eutanasia de la razón. Ensayos sobre el amor y la diferencia. Buenos Aires: Paidós.

De Lauretis, Teresa (2000). Irreductibilidad del deseo y conocimiento del límite. En T. De Laurentis (Ed.), Diferencias. Etapas de un camino a través del feminismo. Madrid: Horas y horas.

Fernández, Ana María (1999). Orden simbólico. ¿orden político? Foros temáticos. Psicoanálisis, estudios feministas y género. http://www.psicomundo.com/foros/genero/orden.htm.

Fernández, Ana María (Ed.). (2006). Política y subjetividad. Asambleas barriales y fábricas recuperadas. Buenos Aires: Tinta Limón.

Flax, Jane (1990). Psicoanálisis y feminismo. Pensamientos fragmentarios. Valencia: Cátedra. 1995. Horney, K. (1967). Psicología femenina. Madrid: Alianza. 1977.

Foucault, Michel (1976). Histoire de la sexualité, I: La volonté de savoir. Paris: Gallimard.

Foucault, Michel (1977). Le jeu de Michel Foucault. En Dits et écrits. Vol.III (pp. 298-329). Paris: Gallimard. 1994.

Heath, Stephen (1986). Joan riviere and the masquerade. In V. Burgin, J. Donald \& C. Kaplan (Eds.), Formations of fantasy (pp. 45-61). London; New York: Methuen.

Horney, Karen (1967). Psicología femenina. Madrid: Alianza. 1977.

Hughes, Athol (1997). Personal experiences-professional interests: Joan Riviere and feminity. The International Journal of Psychoanalysis(78), 899-911.

Mitchell, Juliet (1974). Psychoanalysis and feminism: A radical reassessment of freudian psychoanalysis. New York: Basic Books. Reed. 2000.

Pujal i Llombart, Margot (2006). Vulnerabilidad, sujeción e identidad de género. Espacios para la resistencia feminista. Ponencia presentada en: Sinergias invisibles. III Jornadas sobre violencia de género y VIH, Madrid, 28 de noviembre de 2006.

Tubert, Silvia (1988). La sexualidad femenina y su construcción imaginaria. Madrid: El arquero.

Tubert, Silvia (2003). ¿Psicoanálisis y género? In S. Tubert (Ed.), Del sexo al género. Los equívocos de un concepto (pp. 359-403). Madrid: Cátedra.

Zizek, Slavov (1996). La política de la diferencia sexual. Valencia: Episteme. 


\section{Formato de citación}

Amigot, Patricia. (2007). Joan Riviè, la mascarada y la disolución de la esencia femenina. Athenea Digital, 11, 209-218. Disponible en http://psicologiasocial.uab.es/athenea/index.php/atheneaDigital/article/view/373/334.

\section{SOMEREIGHIS RESERVED}

Este texto está protegido por una licencia Creative Commons.

Usted es libre de copiar, distribuir y comunicar públicamente la obra bajo las siguientes condiciones:

Reconocimiento: Debe reconocer y citar al autor original.

No comercial. No puede utilizar esta obra para fines comerciales.

Sin obras derivadas. No se puede alterar, transformar, o generar una obra derivada a partir de esta obra.

$\underline{\text { Resumen de licencia }}$

$\underline{\text { Texto completo de la licencia }}$ 